Research Article

\title{
Seroprevalence of Malaria and Hepatitis B Coinfection among Pregnant Women in Tamale Metropolis of Ghana: A Cross-Sectional Study
}

\author{
Gideon Kofi Helegbe $\left(\mathbb{D},{ }^{1}\right.$ Paul Armah Aryee ${ }^{D},{ }^{2}$ Baba Sulemana Mohammed (D), 3 \\ Anthony Wemakor $\mathbb{D}^{2},{ }^{2}$ David Kolbila, ${ }^{4}$ Abdul-Wahid Abubakari, ${ }^{5}$ Salam Askanda, ${ }^{5}$ \\ Rashid Alhassan, ${ }^{5}$ Collins Barnie $\mathbb{D}^{5},{ }^{5}$ Afua Aboagyewaa Donkoh, ${ }^{5}$ and Ernest Ofosu ${ }^{5}$ \\ ${ }^{1}$ Department of Biochemistry and Molecular Medicine, School of Medicine and Health Sciences (SMHS), \\ University for Development Studies (UDS), Tamale, Ghana \\ ${ }^{2}$ Department of Nutritional Sciences, School of Allied Health Sciences (SAHS), University for Development Studies (UDS), \\ Tamale, Ghana \\ ${ }^{3}$ Department of Pharmacology, School of Medicine and Health Sciences (SMHS), University for Development Studies (UDS), \\ Tamale, Ghana \\ ${ }^{4}$ Department of Obstetrics and Gynaecology, School of Medicine and Health Sciences (SMHS), University for Development Studies \\ (UDS), Tamale, Ghana \\ ${ }^{5}$ Department of Nursing, School of Allied Health Sciences (SAHS), University for Development Studies (UDS), Tamale, Ghana
}

Correspondence should be addressed to Gideon Kofi Helegbe; kofigidi@yahoo.com

Received 11 April 2018; Revised 29 June 2018; Accepted 22 July 2018; Published 24 September 2018

Academic Editor: Christian Bautista

Copyright (C) 2018 Gideon Kofi Helegbe et al. This is an open access article distributed under the Creative Commons Attribution License, which permits unrestricted use, distribution, and reproduction in any medium, provided the original work is properly cited.

Background. Coinfections are becoming common risk factors that may contribute to the increased burden of morbidity in pregnancy. The aim of this study was to assess the seroprevalence of coinfections of malaria, hepatitis B (HBV), human immunodeficiency virus (HIV), and syphilis among pregnant women attending antenatal clinics (ANC) in the Tamale Metropolis. Methods. By means of rapid diagnostic tests (RDTs), pregnant women attending the Tamale Teaching Hospital (TTH) were screened for malaria, HBV infection, HIV infection, and syphilis from March 2013 to February 2015. Haemoglobin (Hb) values, sickling, and glucose-6-phosphate dehydrogenase deficiency (G6PDd) statuses were also assessed using full blood count (FBC), sodium metabisulphite, and methaemoglobin reduction tests, respectively. Logistic regression analysis was performed to estimate the risks/odds ratios (ORs) for the coinfections and other variables (age, gravidity, and time of the first ANC visit) with 95\% confidence intervals (CIs) and set $p$ values for accepting any differences at $<0.05$. Results. Within the two-year study period, data were collected from 3,127 pregnant women. The mean age (SD) of the pregnant women was $28.5( \pm 5.0)$ years. Of the total number, seroprevalence was high for malaria (11.6\%) and HBV infection (4.2\%) and low for HIV infection (1.0\%) and syphilis (0.4\%) monoinfections. Mal/HBV coinfection was higher (0.7\%) when compared with Mal/HIV (0.1\%), Mal/syphilis $(0.0 \%), \mathrm{HBV} / \mathrm{HIV}$ $(0.0 \%), \mathrm{HBV} /$ syphilis $(0.1 \%)$, and HIV/syphilis $(0.0 \%)$ coinfections. The mean $\mathrm{Hb}(\mathrm{g} / \mathrm{dl})$ for the women with the four monoinfections was significantly different from one another $(p=0.009)$. Pregnant women with malaria infection were about 2 times more likely to be coinfected with HBV even after adjusting for potential confounders (adjusted odds ratio $(A O R)=1.66,95 \%$ $\mathrm{CI}=1.04-2.65, p=0.031$ ). Those in their third trimester and visiting the ANC for the first time were significantly less likely to be infected with $\mathrm{HBV}(\mathrm{AOR}=0.45,95 \% \mathrm{CI}=0.28-0.73, p=0.001)$, with malaria/HBV coinfection $(\mathrm{AOR}=0.09,95 \% \mathrm{CI}=0.01-0.68$, $p=0.020)$, and with any coinfection $(\mathrm{AOR}=0.19,95 \% \mathrm{CI}=0.06-0.63, p=0.007)$. Conclusion. A comparatively high seroprevalence of malaria and its coinfection with HBV in pregnant women was observed in this study. Considering the effects that both malaria and HBV have on the liver, it would be expedient to conduct further studies to assess liver function among malaria/HBV-infected individuals, while interventions to prevent coinfections among pregnant women are intensified. 


\section{Background}

Infectious diseases continue to remain life-threatening and a major public health problem globally. Children under 5 years and pregnant women remain most vulnerable to infectious diseases. While monoinfections have shown to be significant risk factors for poor pregnancy outcomes (e.g., low birth weight, anaemia, early foetal loss, stillbirth, and prematurity) among pregnant women $[1,2]$, studies that evaluated the impact of coinfections on the health of pregnant women [3-5] have come out with some relevant findings, albeit limited by relatively smaller sample sizes. Most of these studies have focused on soil-transmitted helminth (STH) and malaria [4, 6], TB [5], and human immunodeficiency virus (HIV) [7]. While malaria, HBV, and HIV infections are among the topmost diseases affecting many Ghanaians [8], including these pregnant women, syphilis infection among pregnant women is showing a rather disturbing global trend with concomitant adverse pregnancy outcomes $[9,10]$.

Malaria is well endemic in Ghana and has remained a public health problem in pregnancy. Among pregnant women, it accounts for $28.1 \%$ of out-patient department (OPD) attendance, $13.7 \%$ of admissions, and $9.0 \%$ of deaths [11]. Generally, persons living in areas of high transmission are known to acquire immunity to the disease over time [12]. However, in pregnancy, a suppression of the immune system rather occurs $[13,14]$, especially for primigravidae who tend to have a higher risk of malarial infection. Malaria in the pregnant woman, even when asymptomatic, can be serious and a major contributor to low neonatal birth weight, maternal anaemia, infant mortality, spontaneous abortion, and stillbirths $[6,15]$. Coinfections of malaria with other infectious diseases have also been shown to have other outcomes. For instance, individuals coinfected with Plasmodium sp. and HBV present with lower parasitaemia and higher viremia [16]. This is because malaria infection is associated with strong $\mathrm{CD}^{+}$cell activation and upregulation of proinflammatory cytokines, which provides an ideal microenvironment for the spread of the HIV-1 among the $\mathrm{CD}^{+}$cells and thus for rapid viral replication [17]. Malaria/HIV coinfection has been shown to have the following effects: low $\mathrm{Hb}$ [18-20], low CD4 count in the first trimester [21], and low birth weight, fever, and urinary tract infection [20] among others.

The HBV monoinfection is a serious and common infectious disease of the liver. The World Health Organization (WHO) in 2009 reported HBV to infect nearly 2 billion people around the globe, including pregnant women. Activities such as unprotected sex, blood transfusion, tattoo, and sharing unprotected needles and blades predispose individuals to HBV including pregnant women [22]. In view of its potential deleterious effects on maternal and neonatal outcomes, the need for pregnant women to know their status much earlier is achieved by routine screening provided at the ANC. While some studies have documented high $\mathrm{HBV}$ infection prevalence $(>8 \%)$ in Ghana $[23,24]$, data on its prevalence among pregnant women are scanty $[25,26]$. Seroprevalence of HBV (8.03\%) and HIV (17.3\%) has been reported in a study in pregnant women in Tanzania [27]. Even though the mode of transmission of HBV is similar to that of HIV, it is 50 to 100 times more infectious [21]. A study among pregnant women indicates that $3.1 \%$ of $\mathrm{HIV} / \mathrm{HBV}$-seropositive women were $\mathrm{HBeAg}$ [28], where significantly higher HBV DNA load was also observed in these HIV/HBV-coinfected women. Coinfection of $\mathrm{HBV} /$ syphilis is, however, not common.

Infection with HIV for some decades has remained a major public health concern, especially in pregnant women $[29,30]$. In the eastern region of Ghana, an overall HIVpositive prevalence of $8 \%$ has been shown among pregnant women [1]. The significant association between HIV infection and HBsAg-positive status and older age ( $>35$ years) was also reported. This situation results in low CD4 count, which lowers immune status and leaves the affected individual immunocompromised. In view of that, individuals are prone to opportunistic infections such as TB [30] and HBV infections.

With respect to syphilis infection, over two million pregnancies worldwide are affected annually, resulting in adverse pregnancy outcomes and severe sequelae in the newborn [9, 10]. As part of the expanded programme on immunisation (EPI), Ghana's Health Policy recommends antenatal syphilis screening and treatment of positive clients to prevent vertical transmission [31]. Unfortunately, data available are scanty to further influence policy direction. The few studies that exist report $5.5 \%$ prevalence [10] using the point-of-care (POC) test. However, syphilis coinfection with other infections in pregnant women is not common.

Taken together, the impact of these major infectious diseases briefly reviewed here could significantly influence the health and well-being of pregnant women and their foetuses as either mono- or coinfections. Nevertheless, the literature on the coinfection seroprevalence of malaria, $\mathrm{HBV}, \mathrm{HIV}$, and syphilis among pregnant women in Ghana is lacking. Therefore, the objective of this study was to investigate the seroprevalence of coinfections of these four infectious diseases among pregnant women in Tamale.

\section{Methodology}

2.1. Study Area. The study was conducted in the Tamale Metropolis (Figure 1), specifically at the ANC of the Tamale Teaching Hospital (TTH), which is a tertiary referral hospital that provides health care services to the residents of Tamale Metropolis and all of northern Ghana as well as the neighbouring countries of La Cote d'Ivoire, Burkina Faso, and Togo. The hospital is located in the eastern part of the metropolis. The TTH was chosen because of its location, making it accessible to patients far and near.

2.2. Study Design. A hospital-based cross-sectional study design was employed to assess the seroprevalence of monoand coinfections of 4 different infectious diseases affecting pregnant women attending ANC in the TTH from March 2013 to February 2015. The study population comprised consenting first ANC attendees (pregnant women) in any 


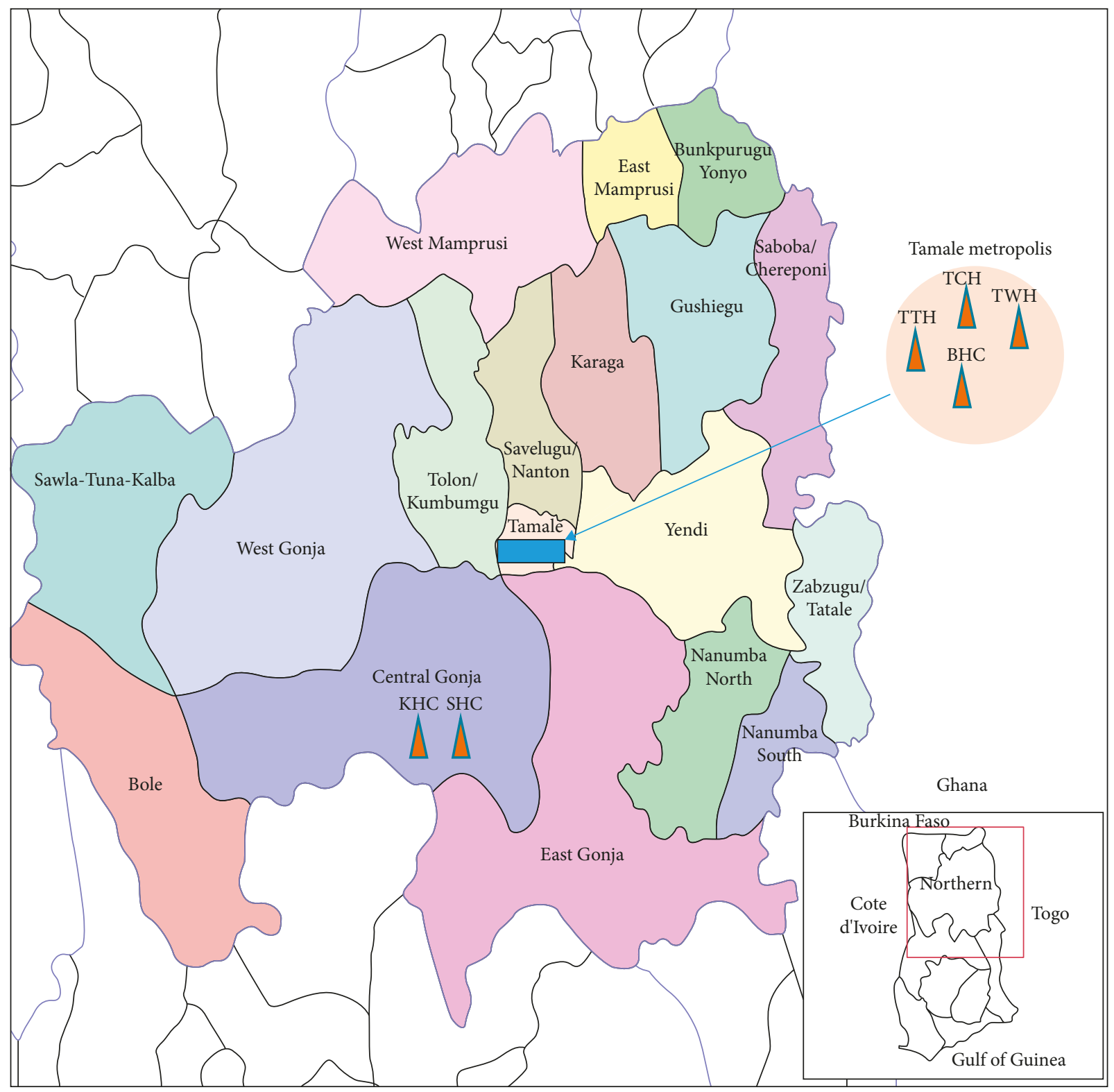

Figure 1: Map of Ghana showing the study area Tamale and neighbouring communities and districts. TTH: Tamale Teaching Hospital; TCH: Tamale Central Hospital; TWH: Tamale West Hospital; BHC: Bilpela Health Centre. These are examples of hospitals and health centers that serve the health needs of Tamale Metropolis and the environs, with TTH as the main referral Hospital.

trimester of pregnancy. By means of the guided questionnaire via interview, age, gravidity, parity, and trimester of the first visit of participants were obtained. Pregnant women who were recruited were those diagnosed of the infections during the study period and were referred by the midwife/nurse for treatment at the health facility. Women were bled twice, at the ANC (for the RDTs) and at the laboratory for the haematological parameters (sickling, $\mathrm{Hb}$, and the G6PD tests).

2.3. Malaria Testing. Malaria was tested on the blood samples collected from the recruited pregnant women using the SD malaria antigen P.f. (Standard Diagnostics, Inc.,
Korea), a rapid diagnostic test (RDT) kit. The RDT kit for Plasmodium falciparum ( $P$. falciparum) was used since $P$. falciparum is the main Plasmodium species in Ghana [3234]. The manufacturer's protocol was strictly adhered to during testing, results reading, and interpretations. This malaria RDT is sensitive to and specific for the identification of $P$. falciparum species as specified by the manufacturers. A positive result was obtained when two colour bands were observed at the test (T) line and the control (C) line in the result window. A negative result was indicated when there was only one colour band at the control (C) line. However, when no colour band was observed at both "C" and "T" columns, or at the " $\mathrm{T}$ " column, the tests were considered invalid and were repeated with new test kits. 
2.4. Hepatitis B Testing. The hepatitis B infection test was conducted according to the manufacturer's instructions (Premier Co. Ltd., India, and Transnational Technologies Inc., UK) using the HBV surface antigen RDT kit, which is sensitive to and specific for the identification of the hepatitis surface antigen as specified by the manufacturers. The manufacturer's protocol was strictly adhered to during testing, results reading, and interpretations. The presence of one purple colour band at the "C" column after the incubation suggested a negative result. The presence of two purple colour bands at the " $\mathrm{C}$ " and " $\mathrm{T}$ " columns indicated a positive result. However, when no purple colour band was observed at both "C" and "T" columns, or at the " $\mathrm{T}$ " column, the tests were considered invalid and were repeated with new test kits.

2.5. HIV Testing. Before the test, a pregnant woman was taken through a pretest counselling session. After the counselling, the rapid diagnostic test, which is sensitive to and specific for the identification of HIV infection as specified by the manufacturers, was performed according to the manufacturer's instructions (Premier Co. Ltd., India, and Transnational Technologies Inc., UK). Results reading and interpretations of findings were done per the manufacturer's protocol. To be sure a subject was positive for HIV, a confirmatory test was performed using the OraQuick confirmation test (Premier Co. Ltd., India, and Transnational Technologies Inc., UK). The manufacturer's protocol was strictly adhered to during testing, results reading, and interpretations. In both Rapid First Response test and OraQuick test for HIV, when the result is positive, a black colour band is observed at the control line $\mathrm{C}$; no colour band at $\mathrm{C}$ means the result is invalid and that card is faulty, and as such, the result was rejected and the test was done again with a new set of kits.

2.6. Syphilis Testing. The syphilis test was also conducted according to the manufacturer's instructions. The TP (Treponema pallidum) kit (INNOVITA (Tangshan) Biological Technology Co., Ltd., China) was used for the syphilis RDT. This RDT is sensitive to and specific for the identification of Treponema pallidum species as specified by the manufacturers. The manufacturer's instructions were strictly adhered to during testing, results reading, and interpretations. The development of two purple bands at both $\mathrm{T}$ line and $\mathrm{C}$ line indicated positive results. A negative result was obtained when only one purple colour band was observed at the $\mathrm{C}$ line. However, an invalid result was observed when no purple band appeared at the $\mathrm{C}$ line. In this case, the result was rejected and repeated again using a fresh test kit.

\subsection{Haematological Testing}

2.7.1. Hb Estimation. Full blood count (FBC) analysis was used to estimate the $\mathrm{Hb}$ level among the subjects. About $5 \mathrm{ml}$ of venous blood was collected into an EDTA tube. The venous blood was mixed with the anticoagulant (EDTA $2 \mathrm{~K}$,
EDTA-3K, or EDTA-2Na) using a sample roller for a minute. The blood sample was then analyzed using the Sysmex XS-500i (Kobe, Japan). The Hb value was extracted from the FBC-printed data.

2.7.2. Sickling Test. A drop of the patient's capillary blood or well-mixed venous blood was delivered on a slide. An equal volume of a fresh reducing reagent (disodium disulphite) was added, gently mixed, and covered with a cover glass. Air bubbles were excluded. A negative control and a positive control were set up alongside the sample and taken through the same treatment. After 10-20 minutes, the patient's preparation was then examined microscopically for sickle cells. Based on the outcome in relation to the negative and positive controls, the test preparation was reported as "sickle cell test positive" or "sickle cell test negative."

\subsubsection{Glucose-6-phosphate Dehydrogenase (G6PD) Test.} The methaemoglobin reduction test was used as described elsewhere [35]. Based on the methaemoglobin reduction test, the recruited pregnant women who were screened for the G6PD activity were classified as normal, partial, or full defect.

2.8. Data Analysis. Data were entered into a spreadsheet using Microsoft Excel. Then, analyses were done using Stata (version 9). Summary output tables of percentage distribution were produced for categorical variables and mean and standard deviation for continuous variables. Logistic regression analysis was used to compute odds ratios and to identify the factors significantly associated with mono- and coinfections. For all tests of association, $p<0.05$ was considered statistically significant.

2.9. Ethical Clearance. Ethical clearance was obtained from the School of Medicine and Health Sciences/School of Allied Health Sciences (SMHS/SAHS) joint institutional review board (IRB), protocol number SMHS/SAHS/ER/0005. Permission was also given by the administrators of the TTH before the data were collected. Informed consent was obtained from all study subjects. However, assent was obtained from those who were below 18 years, before consent was obtained from their spouses or guardians if they were not married. All eligible subjects were provided with information about the aim and content of the study. The participants were also informed that their participation was voluntary and that they could withdraw from the study at any time without consequences and all responses received would be kept confidential.

\section{Results}

3.1. Seroprevalence of Malaria, Hepatitis B, HIV, and Syphilis among the Pregnant Women. During the two-year study period, 3,264 pregnant women attended ANC at Tamale Teaching Hospital, and out of these, 3,127 women consented to participate in the study and were enrolled. The 
TABLE 1: Sociodemographic characteristics of the pregnant women who attended ANC at Tamale Teaching Hospital $(n=3,127)$.

\begin{tabular}{|c|c|c|}
\hline Characteristic & Frequency & Percentage (\%) \\
\hline \multicolumn{3}{|c|}{ Age group (years) } \\
\hline $15-19$ & 72 & 2.3 \\
\hline $20-24$ & 622 & 19.9 \\
\hline $25-29$ & 1,143 & 36.6 \\
\hline $30-34$ & 874 & 28.0 \\
\hline $35-39$ & 354 & 11.3 \\
\hline $40+$ & 62 & 2.0 \\
\hline Total & 3,127 & 100.0 \\
\hline \multicolumn{3}{|l|}{ Gravidity } \\
\hline 1 & 670 & 21.4 \\
\hline 2 & 768 & 24.5 \\
\hline 3 & 617 & 19.7 \\
\hline 4 & 487 & 15.6 \\
\hline 5 & 312 & 10.0 \\
\hline 6 & 190 & 6.1 \\
\hline 7 & 59 & 1.9 \\
\hline $8+$ & 24 & 0.8 \\
\hline Total & 3,127 & 100.0 \\
\hline \multicolumn{3}{|l|}{ Parity } \\
\hline 0 & 760 & 24.4 \\
\hline 1 & 759 & 24.4 \\
\hline 2 & 614 & 19.7 \\
\hline 3 & 461 & 14.8 \\
\hline 4 & 297 & 9.5 \\
\hline 5 & 162 & 5.2 \\
\hline 6 & 45 & 1.4 \\
\hline $7+$ & 19 & 0.6 \\
\hline Total $^{1}$ & 3,117 & 100.0 \\
\hline \multicolumn{3}{|c|}{ Trimester of the first ANC visit } \\
\hline First & 1,213 & 38.8 \\
\hline Second & 1,051 & 33.6 \\
\hline Third & 863 & 27.6 \\
\hline Total & 3,127 & 100.0 \\
\hline
\end{tabular}

${ }^{1}$ Parity has 10 missing cases.

remaining 137 women who declined to participate gave the following reasons for nonparticipation: lack of time to answer the questionnaire $(n=47,1.5 \%)$, feeling of discomfort $(n=29,0.9 \%)$, language barrier $(n=16,0.5 \%)$, and personal/undisclosed reasons $(n=45)$. The age of the women included in the study ranged from 15 to 46 years with a mean of $28.5 \pm 5.0$ years (Table 1 ). About a quarter of the women $(768,24.5 \%)$ had two previous pregnancies, and a similar percentage $(759,24.4 \%)$ had no child. With respect to haematological characteristics, the mean $\mathrm{Hb}$ was $11.0 \pm 1.4 \mathrm{~g} / \mathrm{dL}$, whilst $182(5.8 \%)$ and $191(6.1 \%)$ of the pregnant women had sickle cell trait and glucose-6phosphate dehydrogenase (G6PD) deficiency, respectively. The most prevalent infection was malaria (362, $11.6 \%)$, followed by HBV $(132,4.2 \%)$. Thirty-one $(31,1.0 \%)$ of them were found to be infected with HIV, while 13 $(0.4 \%)$ had syphilis infection.

Further analyses showed that, for those with monoinfections, 335 (10.7\%) had malaria, 106 (3.4\%) had HBV, 25 $(0.8 \%)$ had HIV, and $10(0.3 \%)$ had syphilis (Table 2$)$. Evaluations of the interactions of infections revealed that 31 (1.0\%) had a combination of any two infections (Table 3 ).
TABLE 2: The seroprevalence of malaria, hepatitis (B), HIV, and syphilis among pregnant women who attended ANC at Tamale Teaching Hospital $(n=3,127)$.

\begin{tabular}{lcc}
\hline Infection & $N$ & $\%$ \\
\hline Malaria & & \\
No & 2,765 & 88.4 \\
Yes & 362 & 11.6 \\
\hline Hepatitis $B$ & & \\
No & 2,995 & 95.8 \\
Yes & 132 & 4.2 \\
\hline HIV & & \\
No & 3,096 & 99.0 \\
Yes & 31 & 1.0 \\
\hline Syphilis & & \\
No & 3,114 & 99.6 \\
Yes & 13 & 0.4 \\
\hline
\end{tabular}

TABle 3: The seroprevalence of coinfections among pregnant women who attended ANC at Tamale Teaching Hospital $(n=3,127)$.

\begin{tabular}{|c|c|c|}
\hline Coinfection & $N$ & $\%$ \\
\hline $\begin{array}{l}\text { Malaria and hepatitis } B \\
\text { No } \\
\text { Yes }\end{array}$ & $\begin{array}{c}3,104 \\
23\end{array}$ & $\begin{array}{c}99.3 \\
0.7\end{array}$ \\
\hline $\begin{array}{l}\text { Malaria and HIV } \\
\text { No } \\
\text { Yes }\end{array}$ & $\begin{array}{c}3,123 \\
4\end{array}$ & $\begin{array}{c}99.9 \\
0.1\end{array}$ \\
\hline $\begin{array}{l}\text { Malaria and syphilis } \\
\text { No } \\
\text { Yes }\end{array}$ & $\begin{array}{c}3,127 \\
0 \\
\end{array}$ & $\begin{array}{c}100.0 \\
0.0\end{array}$ \\
\hline $\begin{array}{l}\text { HIV and syphilis } \\
\text { No } \\
\text { Yes }\end{array}$ & $\begin{array}{c}3,126 \\
1 \\
\end{array}$ & $\begin{array}{c}100.0 \\
0.0 \\
\end{array}$ \\
\hline $\begin{array}{l}\text { HIV and hepatitis } B \\
\text { No } \\
\text { Yes }\end{array}$ & $\begin{array}{c}3,126 \\
1\end{array}$ & $\begin{array}{c}100.0 \\
0.0\end{array}$ \\
\hline $\begin{array}{l}\text { Syphilis and hepatitis } B \\
\text { No } \\
\text { Yes }\end{array}$ & $\begin{array}{c}3,125 \\
2 \\
\end{array}$ & $\begin{array}{c}99.9 \\
0.1\end{array}$ \\
\hline $\begin{array}{l}\text { Any coinfection* } \\
\text { No } \\
\text { Yes }\end{array}$ & $\begin{array}{c}3,096 \\
31\end{array}$ & $\begin{array}{c}99.0 \\
1.0\end{array}$ \\
\hline
\end{tabular}

${ }^{*}$ Any coinfection refers to a combination of any of the abovementioned coinfections.

Out of the coinfections, malaria/HBV seroprevalence was the highest $(0.7 \%)$, followed by malaria/HIV $(0.1 \%)$ and syphilis/HepB (0.1\%). For HIV/HBV and HIV/syphilis coinfections, one woman was found in each case.

Within the 2-year period, malaria seroprevalence was revealed to be the highest $(362,11.6 \%)$, followed by hepatitis B (132, 4.2\%) and HIV (31, 1.0\%), with the least being syphilis (13, 0.4\%) (Table 2). Malaria- and HBV-infected cases were noted every month of the study period; however, more cases were observed for malaria than HBV. On the contrary, no cases were reported in some months for HIV and syphilis infections. Within the study population, coinfection of any of the four infections under study was 31 
TABle 4: Associations between malaria and hepatitis B or HIV among pregnant women who attended ANC at Tamale Teaching Hospital $(n=3,127)$.

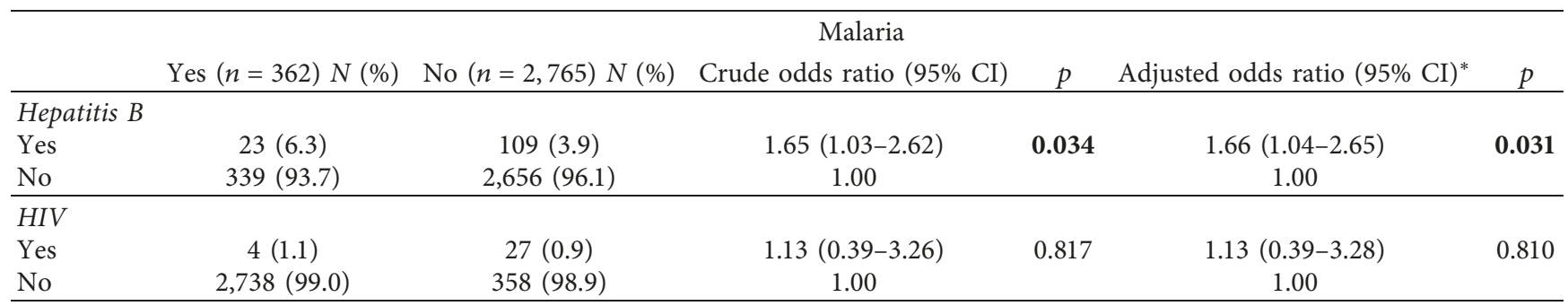

${ }^{*}$ Adjusted for age, trimester of the first ANC visit, and gravidity.

TABLE 5: Age and haematological characteristics of pregnant women with monoinfections who attended ANC at Tamale Teaching Hospital $(n=3,127)$.

\begin{tabular}{lcccc}
\hline Characteristics & & \multicolumn{3}{c}{ Infection type } \\
& Malaria & Hepatitis B & HIV & Syphilis \\
\hline$n(\%)^{*}$ & $335(10.7)$ & $106(3.4)$ & $25(0.8)$ & $10(0.3)$ \\
Mean age (SD) (years) & $28.2(5.2)$ & $29.4(4.4)$ & $29.4(5.4)$ & $26.0(4.4)$ \\
Mean Hb ${ }^{\mathrm{a}}$ (SD) (g/dL) & $10.8(1.5)$ & $11.3(1.4)$ & $10.8(1.5)$ & $11.9(1.4)$ \\
Sickling, $n(\%)^{* *}$ & $24(7.2)$ & $11(10.4)$ & $3(12.0)$ & $0.06^{\#}$ \\
G6PDd, $n(\%)^{* *}$ & $20(6.0)$ & $7(6.6)$ & $3(12.0)$ & $0.009^{\#}$ \\
\hline
\end{tabular}

G6PDd = glucose-6-phosphate dehydrogenase deficiency. ${ }^{\mathrm{a}} \mathrm{Hb}$ was estimated in the pregnant women at the first time of ANC visit; \#analysed by ANOVA. Only single infections were captured in the table. ${ }^{*}$ Percentages were calculated based on the total study subjects of $3,127 .{ }^{* *}$ Percentages were calculated based on total infection for each column.

(1.0\%), with malaria-HBV coinfection being the highest (23, $0.7 \%$ ) (Table 3).

To evaluate how malaria interacted with HBV and HIV, the chances of being infected with HBV and HIV were tested for those with malaria monoinfection and are indicated in Table 4. As shown in the table, infection with malaria was associated with HBV infection. This scenario was still observed when age, trimester of the first ANC visit, and gravidity were adjusted for.

\subsection{Age and Haematological Parameters among Pregnant} Women with Mono- and Coinfections. Pregnant women with syphilis were relatively younger, even though the difference was not significant $(p=0.06)$ (Table 5). Mean $\mathrm{Hb}$ levels differed significantly among different infections $(p=0.009)$. Lowest mean $\mathrm{Hb}$ was recorded among those with malaria and HIV, while pregnant women with syphilis recorded the highest mean $\mathrm{Hb}$. Since haemoglobinopathies are known to have an effect on $\mathrm{Hb}$ levels of affected individuals, the distribution of some haemoglobinopathies (sickle cell trait and G6PDd) among the pregnant women was evaluated. Compared to the other infections, higher proportion of pregnant women with malaria had sickle cell trait $(24,7.2 \%)$ or G6PDd (20, 6.0\%) (Table 5). Furthermore, pregnant women with $\mathrm{HBV} /$ syphilis coinfections were more likely to be younger, while those with HIV/syphilis coinfection were older (Table 6). The mean $\mathrm{Hb}$ level of pregnant women with malaria/HIV coinfection was more likely to be lower than that of those with other coinfections. Only one pregnant woman was found with G6PDd in the malaria/HIV coinfection group, whilst 2 were in the malaria/HBV group
(Table 6). It was observed that no pregnant woman had more than 2 coinfections.

3.3. Relating Age, Trimester of the First ANC Visit, and Gravidity with Malaria, Hepatitis B, and HIV Infections among the Pregnant Women. Evaluating the relationship between age of pregnant women, time of the first ANC visit, and gravidity with malaria infection and malaria/HBV coinfection, no significant associations emerged between age, time of the first ANC visit, and gravidity with malaria infection (Table 7). However, women who for the first time attended ANC in the third trimester of their pregnancy were significantly less likely to be infected with HBV monoinfection or malaria/HBV compared to those who attended ANC in the first or second trimester even after adjusting for age and gravidity. When any coinfection was assessed, consistently, it was observed that pregnant women were significantly less likely to have a coinfection if they initiated ANC during the third or second trimester compared to the first trimester even after adjusting for age and gravidity.

\section{Discussion}

It is obvious from the study that there are interactions among malaria, HBV, HIV, and syphilis infections among pregnant women in Tamale manifesting as coinfections in some individuals. To the best of our knowledge, there are no studies in Ghana or the West African subregion that considered these four infections at the same time in pregnant women.

In this current study, malaria seroprevalence was observed every month of the year, which was consistent with 
TABLE 6: Age and haematological characteristics of pregnant women with coinfection who attended ANC at Tamale Teaching Hospital $(n=3,127)$.

\begin{tabular}{|c|c|c|c|c|c|c|}
\hline \multirow{2}{*}{ Characteristics } & \multicolumn{6}{|c|}{ Coinfection type } \\
\hline & $\mathrm{Mal}+\mathrm{HBV}$ & $\mathrm{Mal}+\mathrm{HIV}$ & Mal + syphilis & $\mathrm{HBV}+\mathrm{HIV}$ & HBV + syphilis & HIV + syphilis \\
\hline$n(\%)^{*}$ & $23(0.7)$ & $4(0.1)$ & $0(0)$ & $1(0.0)$ & $2(0.1)$ & $1(0.0)$ \\
\hline Mean age (SD) (years) & $27.8(3.3)$ & $27.7(4.8)$ & $0(0.0)$ & $29.0(0.0)$ & $26.0(8.4)$ & $33(0.0)$ \\
\hline Mean $\mathrm{Hb}^{\mathrm{a}}(\mathrm{SD})(\mathrm{g} / \mathrm{dL})$ & $11.2(1.6)$ & $10.4(0.8)$ & $0(0)$ & $12.4(0.0)$ & $11.3(0.8)$ & $11.0(0.0)$ \\
\hline Sickling, $n(\%)^{* *}$ & $2(8.7)$ & $2(50.0)$ & $0(0)$ & $0(0)$ & $0(0)$ & $0(0)$ \\
\hline G6PDd, $n(\%)^{* *}$ & $2(8.7)$ & $1(25.0)$ & $0(0)$ & $1(100.0)$ & $0(0)$ & $0(0)$ \\
\hline
\end{tabular}

$\mathrm{G} 6 \mathrm{PDd}=$ glucose- 6 -phosphate dehydrogenase deficiency. ${ }^{\mathrm{a}} \mathrm{Hb}$ was estimated in the pregnant women at the first time of ANC visit. ${ }^{*}$ Percentages were calculated based on the total study subjects of 3,127 . ${ }^{* *}$ Percentages were calculated based on total coinfection for each column.

TABle 7: Association of malaria, hepatitis B, or malaria and hepatitis B coinfection with age, trimester of the first ANC visit, and first pregnancy among pregnant women who attended ANC at Tamale Teaching Hospital $(n=3,127)$.

\begin{tabular}{|c|c|c|c|c|}
\hline Infection/coinfection & Crude odds ratio $(95 \% \mathrm{CI})$ & $p$ & Adjusted odds ratio $(95 \% \mathrm{CI})$ & $p$ \\
\hline \multicolumn{5}{|l|}{ Malaria } \\
\hline \multicolumn{5}{|l|}{ Age group (years) } \\
\hline$\geq 20$ & $0.98(0.62-1.55)$ & 0.926 & $0.96(0.60-1.54)$ & 0.910 \\
\hline$<20$ & 1.00 & & 1.00 & \\
\hline \multicolumn{5}{|c|}{ Trimester of the first ANC visit } \\
\hline First & 1.00 & & 1.00 & \\
\hline Second & $1.17(0.91-1.50)$ & 0.235 & $1.16(0.90-1.50)$ & 0.247 \\
\hline Third & $0.81(0.61-1.07)$ & 0.143 & $0.80(0.60-1.07)$ & 0.139 \\
\hline \multicolumn{5}{|l|}{ Gravidity } \\
\hline Primigravida & $0.95(0.72-1.25)$ & 0.738 & $0.96(0.72-1.26)$ & 0.749 \\
\hline Multigravida & 1.00 & & 1.00 & \\
\hline \multicolumn{5}{|l|}{ Hepatitis $B$} \\
\hline \multicolumn{5}{|l|}{ Age group (years) } \\
\hline$\geq 20$ & $1.33(0.58-3.06)$ & 0.504 & $1.34(0.57-3.13)$ & 0.503 \\
\hline$<20$ & 1.00 & & 1.00 & \\
\hline \multicolumn{5}{|c|}{ Trimester of the first ANC visit } \\
\hline First & 1.00 & & 1.00 & \\
\hline Second & $0.67(0.45-0.99)$ & 0.046 & $0.68(0.45-1.01)$ & 0.059 \\
\hline Third & $0.44(0.27-0.71)$ & 0.001 & $0.45(0.28-0.73)$ & 0.001 \\
\hline \multicolumn{5}{|l|}{ Gravidity } \\
\hline Primigravida & $1.22(0.81-1.83)$ & 0.340 & $1.20(0.80-1.82)$ & 0.379 \\
\hline Multigravida & 1.00 & & 1.00 & \\
\hline \multicolumn{5}{|c|}{ Malaria and hepatitis B coinfection } \\
\hline \multicolumn{5}{|l|}{ Age group (years) } \\
\hline$\geq 20$ & $1.40(0.19-10.40)$ & 0.747 & $1.35(0.18-10.42)$ & 0.773 \\
\hline$<20$ & 1.00 & & 1.00 & \\
\hline \multicolumn{5}{|c|}{ Trimester of the first ANC visit } \\
\hline First & 1.00 & & 1.00 & \\
\hline Second & $0.54(0.22-1.32)$ & 0.175 & $0.55(0.22-1.36)$ & 0.193 \\
\hline Third & $0.09(0.01-0.67)$ & 0.019 & $0.09(0.01-0.68)$ & 0.020 \\
\hline \multicolumn{5}{|l|}{ Gravidity } \\
\hline Primigravida & $1.29(0.51-3.29)$ & 0.594 & $1.23(0.48-3.20)$ & 0.666 \\
\hline Multigravida & 1.00 & & 1.00 & \\
\hline \multicolumn{5}{|c|}{ Any coinfection of the four diseases } \\
\hline \multicolumn{5}{|c|}{ Age group (years) } \\
\hline$\geq 20$ & $0.91(0.22-3.88)$ & 0.907 & $0.79(0.18-3.46)$ & 0.756 \\
\hline$<20$ & 1.00 & & 1.00 & \\
\hline \multicolumn{5}{|c|}{ Trimester of the first ANC visit } \\
\hline First & 1.00 & & 1.00 & \\
\hline Second & $0.38(0.16-0.90)$ & 0.029 & $0.38(0.16-0.90)$ & 0.028 \\
\hline Third & $0.19(0.06-0.64)$ & 0.007 & $0.19(0.06-0.63)$ & 0.007 \\
\hline \multicolumn{5}{|l|}{ Gravidity } \\
\hline Primigravida & $1.07(0.46-2.49)$ & 0.883 & $0.96(0.40-2.27)$ & 0.920 \\
\hline Multigravida & 1.00 & & 1.00 & \\
\hline
\end{tabular}

For the adjusted models, age, trimester of the first ANC visit, and gravidity were considered; whenever the effect of one of these was being investigated, the other two were adjusted for. 
the study by Owusu-Agyei et al. [36]. It was surprising to observe this appreciable number of malaria seroprevalence despite reports showing a high rollout of indoor residual spraying (IRS) programme in the three northern regions compared to the other regions in Ghana [37]. In addition, universal ownership of the insecticide-treated net (ITN) is high in the region $[37,38]$, but as to whether the nets are used appropriately is unknown. Thus, the results point to the fact that these interventions which were aimed at lowering malaria cases significantly within the said regions have not achieved the desired impact. Possible reasons for the high all-year-round malaria cases could include inappropriate use of the ITN and staying outdoors for long periods before getting indoors perhaps owing to the fact that rooms are usually hot especially at night. It is also possible to speculate that the high malaria cases reported all year round could be attributed to the prevalence in the general population of soiltransmitted helminth (STH) infection [39]. Although STH estimations were not carried out in this study, helminths are known to modulate host immune responses in the pregnant woman and to concurrent infections [40]. As a result, pregnant women infected with STH are immunologically compromised and are therefore highly susceptible to parasitic infections such as malaria [41].

While HIV seroprevalence and syphilis seroprevalence were relatively lower throughout the year, seroprevalence of $\mathrm{HBV}$ infection was high. This high prevalence of HBV infection should prompt for an intensified investigation on the history of abortion, surgery, and tattooing as these have been observed to be significantly associated with HBV infections [22]. Our study, however, did not investigate any history of abortion, surgery, and tattooing. High seroprevalence of malaria and HBV monoinfections may have accounted for the level of malaria/HBV coinfection recorded in the current study. HBV DNA load is significantly higher in coinfected pregnant women [28], which our study also confirms with the level of malaria/HBV coinfection. In the current study, the risks of malaria and malaria/HBV coinfection were lower with ANC visit initiation in the second or third trimester compared to the first trimester. As part of the ANC visits, the pregnant women are given sufficient education on preventive measures to minimise the infection rate. Late reporting for ANC is promoted by cultural practices that prohibit the reporting of pregnancies early unless some complications arise. Thus, it is possible that those who initiated ANC earlier did so because of their ill health. This can also be attributed to the cultural preferences of women in these settings to deliver at home and also not to visit ANC. Another important development in the course of HBV and malaria infections is the infective stage during their life cycle. They both invade and multiply within the liver, which might induce some stress on the liver. It was therefore not surprising that pregnant women with HBsAg were observed to have an abnormally high level of alanine aminotransferase (ALAT) [27] in HBV coinfection with another infection, suggesting liver damage.

It is found that those with malaria were significantly more likely to also be infected with $\mathrm{HBV}$ infection and vice versa in our study population. Only, the occurrences of the two infections were assessed, and we did not take into consideration the temporal order of occurrence of the infections and therefore cannot confirm if malaria infection increases the risk of HBV infection or vice versa. The relationship between the two infections is not clear; an increased risk of $\mathrm{HBV}$ infection among persons with severe malaria compared to the general public was observed in Vietnam [42], while another study reported that malariaaffected individuals with active $\mathrm{HBV}$ infection were more likely to be asymptomatic and to present with lower levels of parasitaemia in Brazil [16]. This finding of our study will be explored further in the future, but we invite other investigators to also explore it.

The consequences of malaria and HBV single infections result in low $\mathrm{Hb}$, low $\mathrm{CD} 4$ count in the first trimester, low birth weight, fever, and urinary tract infection (UTI) $[6,15,16,21]$. CD4 cell is very much important in enhancing the immune system in fighting infection via the adaptive immune system. This low CD4 count in the advent of malaria in the first trimester [21] could contribute to the increasing rate of $\mathrm{HBV}$ infections leading to the high malaria/HBV coinfection in the first pregnancy. Malaria and HBV single infections have detrimental impact on the health status of the pregnant woman. In view of this effect, pregnant women coinfected with malaria/HBV should be given prompt and adequate intervention so as to avoid complications.

One consequence of HIV/AIDS among others is that the immune status of these pregnant women becomes poor due to the gradual reduction in the CD4 count. A low seroprevalence rate of syphilis can be attributed to the high use of antibiotics [43] in a section of the Ghanaian population. Antibiotics are normally taken for most bacterial infections, to which syphilis belongs. Meanwhile, our study did not generate any information on antibacterial use among the participants, say in the previous one month, which could be explored in further studies. It is interesting to note that there was no malaria/syphilis coinfection among the pregnant women. Probably, a different immune mechanism and/or other factors may be at play that prevents these two infectious agents from cohabiting. On the contrary, it is noted that there are potential negative impacts on the unborn child, regarding congenital infections and mother-to-child transfer of antibodies, in relation to most of the diseases studied in this paper. These impacts include early foetal loss, stillbirth, prematurity, low birth weight, neonatal and infant death, and congenital disease among newborn babies [44-46].

Sickle cell trait status is a condition that is known to protect individuals from severe malaria. Higher percentage of sickle cell trait among single malaria infection agrees with other studies where sickle cell disease overlaps with malariaendemic regions [47]. This percentage of sickle cell trait occurrence reduced among the pregnant women with malaria/HBV coinfection. Studies have shown that in addition to malaria disease, individuals with sickling are protected from or are associated with other diseases in terms of higher chances of being infected. The chances of HIV infection are lowered by sickle cell disease for about $70 \%$ 
according to an analysis of 423,431 records of adult African Americans admitted to a hospital from 1997 through 2009; it was observed that HIV infection progresses more slowly in people with sickle cell disease [48]. This same report also observed that the chances of infection with HBV or hepatitis $\mathrm{C}$ virus (HCV) are raised by sickle cell disease. The current study revealed that low sickle cell trait cases are observed in the pregnant women who tested positive for HIV, while high sickle cell trait cases of pregnant women were positive for HBV infection. It would have been interesting to see how sickle cell status affects the progression of HBV or HIV/AIDS. Haemoglobin genotyping would have addressed this concern, which this current study did not undertake.

The mean $\mathrm{Hb}$ observed in this current study was within values reported in a similar study (mean $\mathrm{Hb}$ of $9-15 \mathrm{~g} / \mathrm{dL}$ ) among pregnant women from the first to third trimester [49]. The significantly low mean $\mathrm{Hb}$ observed among monoinfected malaria and HIV/AIDS pregnant women signifies the impact these infections, respectively, have on the RBC. It was not surprising that malaria/HIV-coinfected pregnant women recorded the lowest mean $\mathrm{Hb}$ in the current study. Low $\mathrm{Hb}$ observed in malaria is as a result of direct lysis of the RBC due to multiplication of the Plasmodium parasite in $\mathrm{RBC}$ and also by immune mediation [50]. HIV infection on the contrary has been shown to be associated with low $\mathrm{Hb}[18,51]$, and in some cases resulting in anaemic conditions [20]. HIV infection accounts for the low $\mathrm{Hb}$ /anaemic conditions via bone marrow suppression [52], suppression of the erythropoietin [53], and direct effect on the RBC loss [54].

G6PDd is an inherited condition caused by defect(s) in the gene that codes for the enzyme, glucose-6-phosphate dehydrogenase (G6PD). It can cause haemolytic anaemia and jaundice. The deficiency of this enzyme is quite common in areas endemic for Plasmodium infection [55]. Haemolytic anaemia due to G6PDd has been reported in people with HIV and hepatitis C; in hepatitis E individuals, the defect can lead to complications such as renal failure, severe anaemia, haemolysis, and hepatic encephalopathy [56]. At the ANC in TTH, sulphur- and quinine-based antimalarial drugs are used for prophylaxis, and this is a cause for worry, especially when used in pregnant women with G6PD deficiency. This may result in severe haemolysis if not monitored adequately. It is for this reason that pregnant women are screened for G6PD at their first ANC visit. Those with G6PDd are given alternative antimalarial prophylaxis and/or therapy.

Despite the significant data generated in this study, there were some limitations, which should form the basis for future studies to help strengthen the important findings here. The limitations include our inability to study the treatment and pregnancy outcomes of the study population. Furthermore, HBV profiling was not done and parasite's density was not estimated. Also, we used a cross-sectional study design which is not appropriate for studies of cause-and-effect relationships. Despite these limitations, we think the study provides some important insights into the co-occurrence of some common infections among pregnant women in Ghana.

\section{Conclusion}

Seroprevalence of $0.7 \%$ for malaria/HBV coinfection was observed in this study, where those with malaria were significantly more likely to also be infected with HBV infection and vice versa in our study population. Furthermore, risks of malaria and malaria/HBV coinfection were lower with ANC visit initiation in the second or third trimester compared to initiation in the first trimester. Our data can be relied upon to inform medical personnel, especially doctors and nurses, that any pregnant woman infected with malaria should be evaluated for HBV. While intervention on preventive health education needs to be intensified, the proportion of pregnant women with malaria/HBV coinfection calls for further studies to assess liver function among such women since malaria and HBV both adversely affect the liver.

\section{Abbreviations \\ HIV: Human immunodeficiency virus \\ AIDS: Acquired immunodeficiency syndrome \\ ALAT: Alanine aminotransferase \\ ANC: Antenatal clinic \\ CD4: $\quad$ Cluster of differentiation 4 \\ G6PDd: Glucose-6-phosphate dehydrogenase deficiency \\ HBV: Hepatitis B virus \\ HBsAg: Hepatitis B surface antigen \\ HepB: Hepatitis B \\ IRS: Indoor residual spraying \\ ITN: Insecticide-treated nets \\ RDT: $\quad$ Rapid diagnostic test.}

\section{Data Availability}

The datasets supporting the findings of this article are available in this manuscript.

\section{Ethical Approval}

Ethical clearance was sought and obtained from the School of Medicine and Health Sciences/School of Allied and Health Sciences (SMHS/SAHS) joint ethical review board (ERB). Permission was given by the administrators of the Tamale Teaching Hospital (TTH) before the data were collected.

\section{Consent}

Informed consent was obtained from all study subjects. For this, all eligible patients were provided with information about the aim and content of the study. The participants were also informed that their participation was voluntary and that they could withdraw from the interview/study at any time without consequences and all responses received would be kept confidential. They were then asked to sign a written consent form before participating in the study. However, assent was obtained from those who were below 18 years, before consent was obtained from their spouses or the guardians if they were not married. 


\section{Disclosure}

The research did not receive specific funding but was performed as part of the employment of the authors. The name of the employer is University for Development Studies and was not involved in the manuscript writing, editing, approval, or decision to publish.

\section{Conflicts of Interest}

The authors declare that there are no conflicts of interest.

\section{Authors' Contributions}

GKH conceived the study idea. GKH and PAA contributed to the design of the study. GKH, PAA, BSM, DK, and AW recruited the study participants and sought written consent. A-WA, SA, RA, BC, AAD, and OE administered questionnaires and entered the data. GKH, BSM, and DK performed the laboratory analysis. GKH, PAA, and AW contributed to the data analysis. GKH drafted the manuscript with PAA, AW, BSM, and DK. The study was supervised by GKH. All authors read and approved the final version.

\section{Acknowledgments}

Our most profound gratitude goes to the nurses and midwifes at the antenatal clinic and the staff at the hematology unit of the Tamale Teaching Hospital for their immeasurable help. We also extend our heartfelt gratitude to all the pregnant women for participating in the study. Prof. Francis Abantanga is thanked for proof reading our work.

\section{Supplementary Materials}

Supplementary 1. Figure 1: map of Ghana showing the study area Tamale and neighbouring communities and districts. Supplementary 2. Dataset of the subjects. This is an SPSS document containing data transcribed from the questionnaire. (Supplementary Materials)

\section{References}

[1] H. J. Yoon, G. Bonsu, A. Akoto-Ampaw et al., "Prevalence and risk factors for human immunodeficiency virus infection in pregnant women in Eastern Ghana," Brazilian Journal of Infectious Diseases, vol. 16, no. 2, pp. 217-218, 2012.

[2] E. Zemene, D. Yewhalaw, S. Abera, T. Belay, A. Samuel, and A. Zeynudin, "Seroprevalence of Toxoplasma gondii and associated risk factors among pregnant women in Jimma town, Southwestern Ethiopia," BMC Infectious Diseases, vol. 12, no. 1, p. 337, 2012.

[3] E. Ivan, N. J. Crowther, E. Mutimura, L. O. Osuwat, S. Janssen, and M. P. Grobusch, "Helminthic infections rates and malaria in HIV-infected pregnant women on anti-retroviral therapy in Rwanda," PLoS Neglected Tropical Diseases, vol. 7, no. 8, article e2380, 2013.

[4] N. J. Yatich, J. Yi, T. Agbenyega et al., "Malaria and intestinal helminth co-infection among pregnant women in Ghana: prevalence and risk factors," American Journal of Tropical Medicine and Hygiene, vol. 80, no. 6, pp. 896-901, 2009.
[5] A. Kassu, G. Mengistu, B. Ayele et al., "Recently added HIV and intestinal parasites in adult TB patients in a teaching hospital in Northwest Ethiopia," Tropical Doctor, vol. 37, no. 4, pp. 222-224, 2007.

[6] A. A. Adegnika, M. Ramharter, S. T. Agnandji et al., "Epidemiology of parasitic co-infections during pregnancy in Lambaréné, Gabon," Tropical Medicine \& International Health, vol. 15, no. 10, pp. 1204-1209, 2010.

[7] M. Gallagher, I. Malhotra, P. L. Mungai et al., "The effects of maternal helminth and malaria infections on mother-to-child HIV transmission," AIDS, vol. 19, no. 16, pp. 1849-1855, 2005.

[8] April 2017, http://wwwAfro.who.int, http://www.afro.who. int/home/countries/fact_sheet/ghana.pdf.

[9] WHO, Untreated Maternal Syphilis and Adverse Outcomes of Pregnancy: A Systematic Review and Meta-Analysis, World Health Organization, Geneva, Switzerland, April 2017, http:// www.who.int/bulletin/volumes/91/3/12-107623/en/.

[10] A. W. Dzokoto, D. Mabey, Y. Adu-Sarkordie, and N. A. Addo, "O22.1 evaluation of syphilis point of care tests conducted by midwives at primary health facilities in Ghana," Sexually Transmitted Infections, vol. 89, pp. A68-A69, 2013.

[11] Malaria in Pregnancy Training Manual for Health Providers, https://ghanahealthservice.org/downloads/MALARIA.

[12] D. L. Doolan, C. Dobano, and J. K. Baird, "Acquired immunity to malaria," Clinical Microbiology Reviews, vol. 22, no. 1, pp. 13-36, 2009.

[13] A. Leber, M. L. Zenclussen, A. Teles et al., "Pregnancy: tolerance and suppression of immune responses," Methods in Molecular Biology, vol. 677, pp. 397-417, 2010.

[14] A. R. D. McLean, R. Ataide, J. A. Simpson, J. G. Beeson, and F. J. I. Fowkes, "Malaria and immunity during pregnancy and postpartum: a tale of two species," Parasitology, vol. 142, no. 8, pp. 999-1015, 2015.

[15] R. W. Steketee, B. L. Nahlen, M. E. Parise, and C. Menendez, "The burden of malaria in pregnancy in malaria-endemic areas," American Journal of Tropical Medicine and Hygiene, vol. 64 , no. 1 , pp. $28-35$.

[16] B. B. Andrade, C. J. N. Santos, L. M. Camargo et al., "Hepatitis $\mathrm{B}$ infection is associated with asymptomatic malaria in the Brazilian Amazon," PLoS One, vol. 6, no. 5, Article ID e19841, 2011.

[17] A. Alemu, Y. Shiferaw, Z. Addis, B. Mathewos, and W. Birhan, "Effect of malaria on HIV/AIDS transmission and progression," Parasites and Vectors, vol. 6, no. 1, p. 18, 2013.

[18] A. O. Sanyaolu, A. F. Fagbenro-Beyioku, W. A. Oyibo, O. S. Badaru, O. S. Onyeabor, and C. I. Nnaemeka, "Malaria and HIV co-infection and their effect on haemoglobin levels from three healthcare institutions in Lagos, southwest Nigeria," African Health Sciences, vol. 13, no. 2, pp. 295-300, 2013.

[19] S. Rattanapunya, J. Kuesap, W. Chaijaroenkul, R. Rueangweerayut, and K. Na-Bangchang, "Prevalence of malaria and HIV coinfection and influence of HIV infection on malaria disease severity in population residing in malaria endemic area along the Thai-Myanmar border," Acta Tropica, vol. 145, pp. 55-60, 2015.

[20] R. D. Wumba, J. Zanga, M. N. Aloni et al., "Interactions between malaria and HIV infections in pregnant women: a first report of the magnitude, clinical and laboratory features, and predictive factors in Kinshasa, the Democratic Republic of Congo," Malaria Journal, vol. 14, no. 1, p. 82, 2015.

[21] R. S. Houmsou, B. E. Wama, S. O. Elkanah et al., "Malarial infection in HIV infected pregnant women attending a rural 
antenatal clinic in Nigeria," Advances in Epidemiology, vol. 2014, Article ID 694213, 6 pages, 2014.

[22] Z. Desalegn, L. Wassie, H. B. Beyene, A. Mihret, and Y. A. Ebstie, "Hepatitis B and human immunodeficiency virus co-infection among pregnant women in resource-limited high endemic setting, Addis Ababa, Ethiopia: implications for prevention and control measures," European Journal of Medical Research, vol. 21, no. 1, 2016.

[23] J. Dongdem, S. Kampo, I. Soyiri, P. N. Asegba, J. B. Ziem, and K. Sagoe, "Prevalence of hepatitis B virus infection among blood donors at the Tamale Teaching Hospital, Ghana (2009)," BMC. Research Notes, vol. 5, no. 1, p. 115, 2012.

[24] B. Nkrumah, M. Owusu, H. O. Frempong, and P. Averu, "Hepatitis B and C viral infections among blood donors from rural Ghana," Ghana Medical Journal, vol. 45, no. 3, pp. 97-100, 2011.

[25] R. M. Merrill and B. D. Hunter, "Seroprevalence of markers for hepatitis B viral infection," International Journal of Infectious Diseases, vol. 15, no. 2, pp. e78-e121, 2011.

[26] J. K. Acquaye and J. A. Mingle, "Hepatitis B viral markers in Ghanaian pregnant women," West African Journal of Medicine, vol. 13, pp. 134-137, 1994.

[27] J. Manyahi, Y. Msigwa, F. Mhimbira, and M. Majigo, "High sero-prevalence of hepatitis B virus and human immunodeficiency virus infections among pregnant women attending antenatal clinic at Temeke municipal health facilities, Dar es Salaam, Tanzania: a cross sectional study," BMC Pregnancy and Childbirth, vol. 17, no. 1, 2017.

[28] N. V. Thumbiran, D. Moodley, R. Parboosing, and P. Moodley, "Hepatitis B and HIV co-infection in pregnant women: indication for routine antenatal hepatitis B virus screening in a high HIV prevalence setting," South African Medical Journal, vol. 104, no. 4, p. 307, 2013.

[29] C. J. Uneke, D. D. Duhlinska, and E. B. Igbinedion, "Prevalence and public-health significance of HIV infection and anaemia among pregnant women attending antenatal clinics in south-eastern Nigeria," Journal of Health, Population and Nutrition, vol. 25, no. 3, pp. 328-335, 2007.

[30] WHO, HIV/AIDS, World Health Organization, Geneva, Switzerland, 2017, http://www.who./int/mediacentre/ factsheets/fs360/en.

[31] March 2018, https://www.ghanahealthservice.org/downloads/ GHS\%202008\%20Annual\%20Report\%20Rev\%20fin\%201209-09.pdf..

[32] F. P. Mockenhaupt, B. Rong, H. Till et al., "Submicroscopic Plasmodium falciparum infections in pregnancy in Ghana," Tropical Medicine and International Health, vol. 5, no. 3, pp. 167-173, 2000.

[33] E. D. A. Owusu, C. A. Brown, M. P. Grobusch, and P. Mens, "Prevalence of Plasmodium falciparum and non-P. falciparum infections in a highland district in Ghana, and the influence of HIV and sickle cell disease," Malaria Journal, vol. 16, no. 1, p. 167, 2017.

[34] DFID, Malaria: Country Profiles, June 2018, https://www.gov. uk/government/uploads/system/uploads/attachment_data/ file/67476/malaria-country-profiles.pdf.

[35] M. Cheesbrough, District Laboratory Practice in Tropical Countries, Cambridge University Press, Cambridge, UK, 2nd edition, 2010, ISBN-10 0-521-67631-2.

[36] S. Owusu-Agyei, K. P. Asante, M. Adjuik et al., "Epidemiology of malaria in the forest-savanna transitional zone of Ghana," Malaria Journal, vol. 8, no. 1, p. 220, 2009.

[37] Ghana 2014 Demographic and Health Survey, April 2017, http://dhsprogram.com/pubs/pdf/FR307/FR307.pdf.
[38] K. C. Ernst, S. Erly, C. Adusei et al., "Reported bed net ownership and use in social contacts is associated with uptake of bed nets for malaria prevention in pregnant women in Ghana," Malaria Journal, vol. 16, no. 1, 2017.

[39] J. Bethony, S. Brooker, M. Albonico et al., "Soil-transmitted helminth infections: ascariasis, trichuriasis, and hookworm," The Lancet, vol. 367, no. 9521, pp. 1521-1532, 2006.

[40] H. Mpairwe, R. Tweyongyere, and A. Elliott, "Pregnancy and helminth infections," Parasite Immunology, vol. 36, no. 8, pp. 328-337, 2014.

[41] T. W. Mwangi, J. M. Bethony, and S. Brooker, "Malaria and helminth interactions in humans: an epidemiological viewpoint," Annals of Tropical Medicine \& Parasitology, vol. 100, no. 7, pp. 551-570, 2013.

[42] M. J. Barcus, T. T. Hien, N. J. White et al., "Hepatitis B infection and severe Plasmodium falciparum malaria in Vietnamese adults," American Journal of Tropical Medicine and Hygiene, vol. 66, no. 2, pp. 140-142, 2002.

[43] E. S. Donkor, P. B. Tetteh-Quarcoo, P. Nartey, and I. O. Agyeman, "Self-medication practices with antibiotics among tertiary level students in Accra, Ghana: a crosssectional study," International Journal of Environmental Research and Public Health, vol. 9, no. 10, pp. 3519-3529, 2012.

[44] K. Arab, A. R. Spence, N. Czuzoj-Shulman, and H. A. Abenhaim, "Pregnancy outcomes in HIV-positive women: a retrospective cohort study," Archives of Gynecology and Obstetrics, vol. 295, no. 3, pp. 599-606, 2017.

[45] S. Sirilert, K. Traisrisilp, P. Sirivatanapa, and T. Tongsong, "Pregnancy outcomes among chronic carriers of hepatitis B virus," International Journal of Gynecology \& Obstetrics, vol. 126, no. 2, pp. 106-110, 2014.

[46] D. Ingall and P. J. Sánchez, "Syphilis," in Infectious Diseases of the Fetus and Newborn Infant, J. S. Remington and J. O. Klein, Eds., pp. 643-681, W.B. Saunders, Philadelphia, PA, USA, 5th edition, 2001

[47] F. B. Piel, A. P. Patil, R. E. Howes et al., "Global distribution of the sickle cell gene and geographical confirmation of the malaria hypothesis," Nature Communications, vol. 1, no. 8, p. 104, 2010.

[48] M. Nouraie, S. Nekhai, and V. R. Gordeuk, "Sickle cell disease is associated with decreased HIV but higher HBV and HCV comorbidities in US hospital discharge records: a crosssectional study," 2017, http://connection.ebscohost.com/c/ articles/84015386/sickle-cell-disease-associated-decreasedhiv-but-higher-hbv-hcv-comorbidities-us-hospital-dischargerecords-cross-sectional-study.

[49] M. Abbassi-Ghanavati, L. G. Greer, and F. G. Cunningham, "Pregnancy and laboratory studies," Obstetrics \& Gynecology, vol. 114, no. 6, pp. 1326-1331, 2009.

[50] G. K. Helegbe, B. Q. Goka, J. A. L. Kurtzhals et al., "Complement activation in Ghanaian children with severe Plasmodium falciparum malaria," Malaria Journal, vol. 6, no. 1, p. 165, 2007.

[51] B. H. Oladeinde, M. Richard Omoregie, M. Olley, and J. A. Anunibe, "Prevalence of HIV and anemia among pregnant women," North American Journal of Medical Sciences, vol. 3, pp. 548-551, 2011.

[52] S. A. Dhurve and A. S. Dhurve, "Bone marrow abnormalities in HIV Disease," Mediterranean Journal of Hematology and Infectious Diseases, vol. 5, no. 1, article e2013033, 2013.

[53] K. A. Kreuzer, J. Rgen, K. Rockstroh, W. Jelkmann, A. Theisen, and U. Spengler, "Inadequate erythropoietin response to anaemia in HIV patients: relationship to serum levels of tumour necrosis factor-alpha, interleukin- 6 and their 
soluble receptors," British Journal of Haematology, vol. 96, no. 2, pp. 235-239, 1997.

[54] D. Gibellini, A. Clò, S. Morini, A. Miserocchi, C. Ponti, and M. C. Re, "Effects of human immunodeficiency virus on the erythrocyte and megakaryocyte lineages," World Journal of Virology, vol. 2, no. 2, pp. 91-101, 2013.

[55] R. E. Howes, F. B. Piel, A. P. Patil et al., "G6PD deficiency prevalence and estimates of affected populations in malaria endemic countries: a geostatistical model-based map," PLoS Medicine, vol. 9, no. 11, article e1001339, 2012.

[56] A. Monga, R. P. S. Makkar, A. Arora, S. Mukhopadhyay, and A. K. Gupta, "Case report: acute hepatitis E infection with coexistent glucose-6-phosphate dehydrogenase deficiency," Canadian Journal of Infectious Diseases, vol. 14, no. 4, pp. 230-231, 2003. 


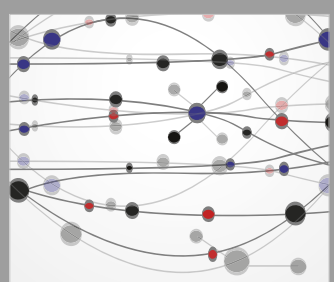

The Scientific World Journal
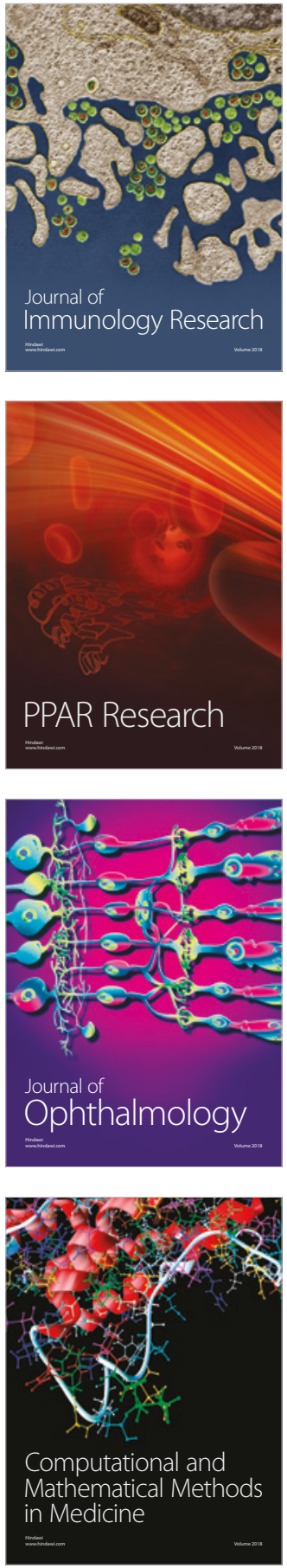

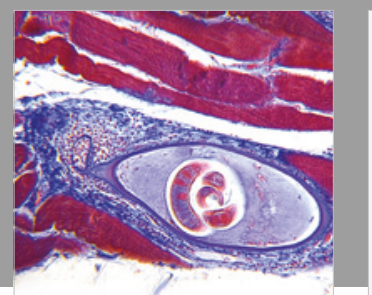

Gastroenterology Research and Practice

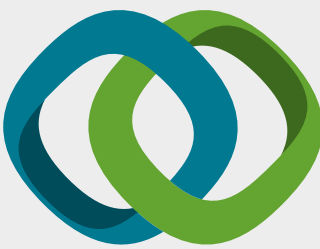

\section{Hindawi}

Submit your manuscripts at

www.hindawi.com
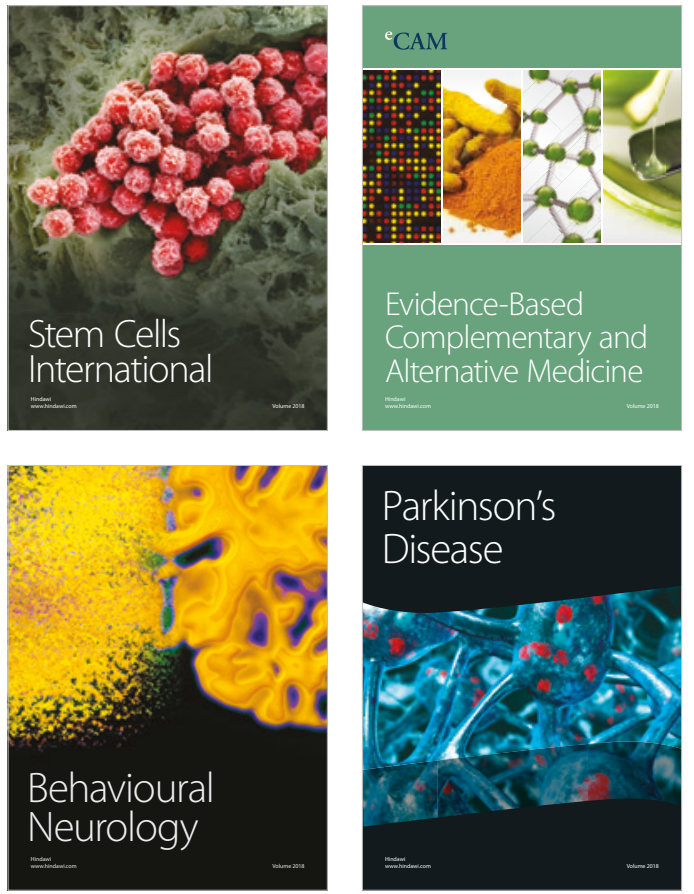

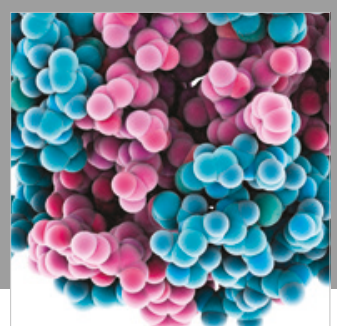

ournal of

Diabetes Research

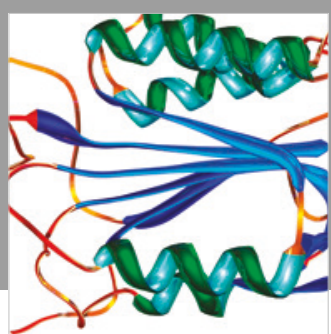

Disease Markers
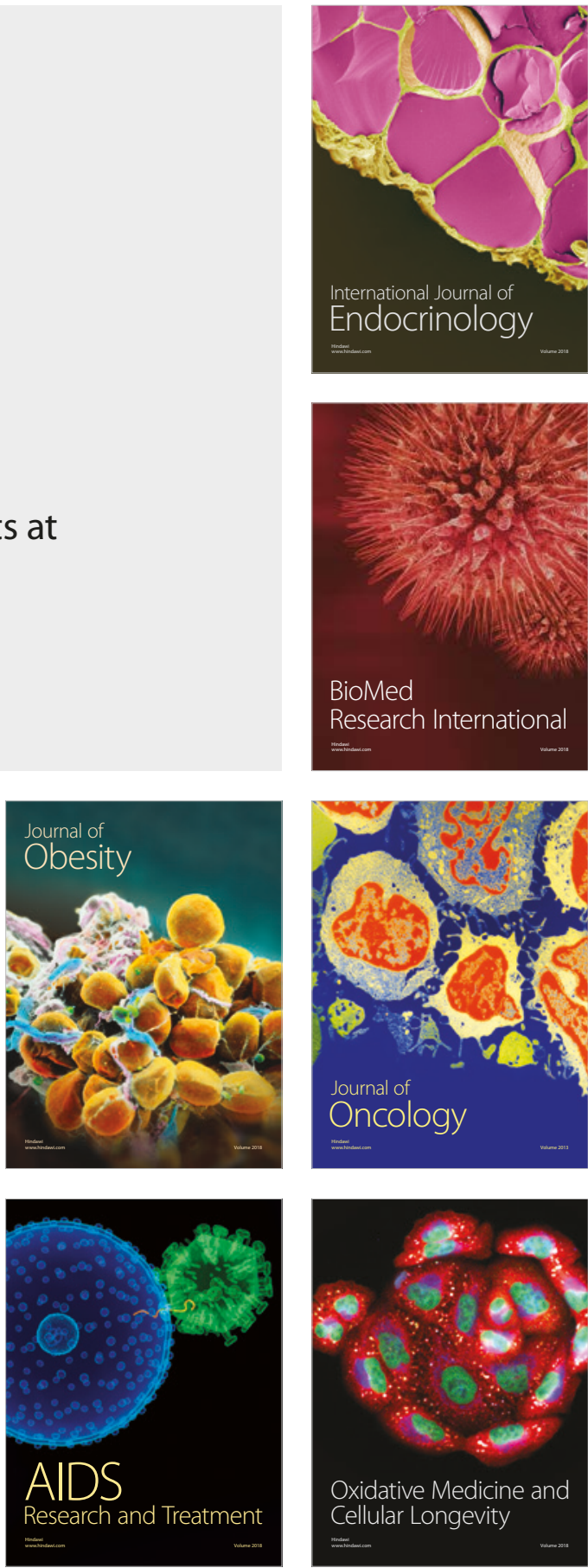